are well defined, and both these features indicate that there has been movement along the contact, so that it may be classed as a fissure lode on an igneous contact. It is certainly too regular in strike to consider it a replacement along what superficially appears to be rather regular igneous contact. Where the gangue is extremely hard indurated schist this is much jointed or broken, further pointing to a settling movement along the contact planes. The lode underlies $75^{\circ}-80^{\circ}$ easterly, which is the dip of the schists on the hanging walls. The gangue in the lode consists of diorite in various stages of alteration, soft weathered schist, and hard indurated schist. Where the last-named occurs replacement appears to be confined to the fracture-faces, which are coated with cobaltite in process of oxidation to erythrite.

A few chains north of No. 4 shaft there are some old abandoned workings on the contact. These were worked for copper, and there is a good deal of copper carbonate associated with the mullock. With the copper occurs a vein of scheelite $2-4$ in. wide, from which well-developed crystals of that mineral have been obtained. Although so closely contiguous, there is no appearance of cobalt stains.

In the diorite dyke in juxtaposition to the cobalt lode there is a quartz outcrop running at right angles to it which contains cobaltiferous wad as well as jasper-brown iron ore. Although it does not meet the cobalt lode at the surface, it has possibly a genetic relationship to the cobalt lode, and it is suggested that it may have been a channel of supply, thus accounting for what, at the present time only, appears a definite localisation of the cobalt in the contact lode. A sample of the wad from this outcrop contained :

$\begin{array}{lllll}\text { Metallic cobalt } & \ldots & \ldots & \ldots & 5 \cdot 2 \text { per cent. } \\ \text { Metallic nickel } & \ldots & \ldots & \ldots & \text { nil }\end{array}$

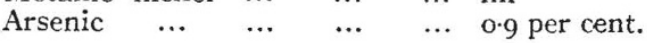

It is very desirable, however, that the whole of the diorite contact should be prospected, particularly the eastern contact, on account of copper carbonates, scheelite, and cobalt ores having been already found along it.

\title{
The Study of British Roses.
}

$\mathrm{T}$ HE study of our British roses has been rendered increasingly difficult by successive attempts to classify the numerous forms-species or varietiesin a satisfactory system. The late Mr. J. G. Baker in his "Monograph of British Roses" in 1869 recognised thirteen species and a moderate number of varieties. In the "London Catalogue of British Plants" (1908) some of Baker's varieties are raised to specific rank, and twenty-five species and a large number of additional varieties are recognised. Wolley-Dod's "List of British Roses" (I9II) included about I7o names, but in his "Revised Arrangement" recently published in the Journal of Botany the number of names having full specific rank is reduced to eighteen, the author remarking that most of the very detailed descriptions of Déséglise and other specialists can scarcely be other than those of an individual bush or specimen which cannot be completely matched by any other.

The present position is discussed in the New Phytologist (vol. xix., Nos. 7 and 8 ) by Mr. J. R. Matthews, who considers that only by culture, combined with cytological study, will it become possible to determine finally the genetic relationships of the numerous micro-species into which old, well-known species like Rosa canina, Linn., have been split. The study of external form has so far failed to give a satisfactory solution of the problem, and the anatomical method followed by Parmentier has not proved more successful. Several hybrids-that is, crossesbetween distinct species have been recognised among British roses, and it is not improbable that the difficulty in classifying the genus may be largely due to hybridisation and segregation, complicated, it may be, by rehybridisation. Hybrids between closely similar parents would be difficult to diagnose, and in actual practice would, as a rule, be considered distinct species or varieties; and it is suggested that a large portion of the total number of named varieties of roses has arisen in this way.

The work of Jeffrey on hybridism in the Rosaceæ indicates that certain recognised species are, from the study of their pollen, in reality concealed hybrids (crypthybrids), and Miss Cole more recently from the study of the pollen in numerous roses concludes that the great majority of so-called species are really of hybrid origin. There is no experimental evidence to show whether these species-hybrids segregate or remain stable; but presuming segregation to occur in the genus Rosa, we might expect to find a large number of visually distinct forms showing various combinations of Mendelian unit-characters, such as hairiness, leaf serration, glandularity, glaucousness, etc.

Mr. Matthews attempts a theoretical analysis of some of the British species of roses on the basis of a few separate characters such as these. The species selected are the aggregate species generally recognised by systematists, and the author suggests that the numerous sub-species and varieties of these aggregates which have been described represent some of the various combinations of unit-characters which might be expected to result from the process of segregation. The argument is confessedly entirely hypothetical, and the author emphasises the importance of experimental work to establish the hypothesis.

\section{Commerce and Customs of Papua. ${ }^{1}$}

$\mathrm{N}$ his Report on the Territory of Papua for the year ending June, 1919, the Lieutenant-Governor, the Hon. J. H. P. Murray, shows that, as in so many other parts of the world, the scarcity and irregularity of shipping facilities are acting prejudicially to the progress and development of the Territory. This is especially indicated by the decrease of exports upon

1 "Commonwealth of Australia. Papua. Annual Report for the Year rgr8-19." Pp. $\mathrm{rr}_{7}+2$ pls. (Printed and Published for the Government the Commonwealth of Australia by Albert J. Mullett, Government Printer for the State of Victoria.)

$$
\text { NO. } 2679 \text {, VOL. IO7] }
$$

which the prosperity of the country mainly depends. Rubber alone showed an increase, but the quantity is as yet small (207 tons as compared with 144 tons in 1918). Another important vegetable export, copra, has decreased $(2598$ tons as compared with 3189 tons in I9I8). Native-made copra forms a large proportion of the output, and, owing to variation in the production, this does not increase steadily like the plantation product. The production of sisal hemp has also decreased, whilst the value of all the crops has been much reduced by a fall in prices. The 